\title{
The strategies for the supplementation of vitamins and trace minerals in pig production: surveying major producers in China
}

\author{
Pan Yang ${ }^{1}$, Hua Kai Wang ${ }^{1}$, Long Xian $\mathrm{Li}^{1}$, and Yong Xi Ma ${ }^{1,2, *}$
}

* Corresponding Author: Yong Xi Ma Tel: +86-10-6273-3588, Fax: +86-10-6273-3688, E-mail: mayongxi2005@163.com

${ }^{1}$ State Key Laboratory of Animal Nutrition, College of Animal Science and Technology, China Agricultural University, Beijing 100193, China

${ }^{2}$ Ministry of Agriculture and Rural Affairs

Feed Industry Centre, Beijing 100193, China

ORCID

Pan Yang

https://orcid.org/0000-0002-2944-8509

Hua Kai Wang

https://orcid.org/0000-0002-8180-1453

Long Xian Li

https://orcid.org/0000-0002-3816-1788

Yong Xi Ma

https://orcid.org/0000-0001-7892-5618

Submitted Jul 22, 2020; Revised Aug 19, 2020; Accepted Oct 27, 2020
Objective: Adequate vitamin and trace mineral intake for pigs are important to achieve satisfactory growth performance. There are no data available on the vitamin and trace mineral intake across pig producers in China. The purpose of this study was to investigate and describe the amount of vitamin and trace minerals used in Chinese pig diets.

Methods: A 1-year survey of supplemented vitamin and trace minerals in pig diets was organized in China. A total of 69 producers were invited for the survey, which represents approximately $90 \%$ of the pig herd in China. Data were compiled by bodyweight stages to determine descriptive statistics. Nutrients were evaluated for vitamin A, vitamin D, vitamin $E$, vitamin $K$, thiamine, riboflavin, vitamin $B_{6}$, vitamin $B_{12}$, pantothenic acid, niacin, folic acid, biotin, choline, copper, iron, manganese, zinc, selenium, and iodine. Data were statistically analyzed by functions in Excel.

Results: The results indicated variation for supplemented vitamin (vitamin A, vitamin $\mathrm{D}$, vitamin $\mathrm{E}$, vitamin $\mathrm{K}$, vitamin $\mathrm{B}_{12}$, pantothenic acid, niacin, and choline) and trace minerals (copper, manganese, zinc, and iodine) in pig diets, but most vitamins and trace minerals were included at concentrations far above the total dietary requirement estimates reported by the National Research Council and the China's Feeding Standard of Swine. Conclusion: The levels of vitamin and trace mineral used in China's pig industry vary widely. Adding a high concentration for vitamin and trace mineral appears to be common practice in pig diets. This investigation provides a reference for supplementation rates of the vitamins and trace minerals in the China's pig industry.

Keywords: China; Pig Industry; Supplementation Level; Trace Mineral; Vitamin

\section{INTRODUCTION}

Although vitamins and minerals constitute a relatively small percentage of the diet, they are vital to health, well-being, and performance, each of them plays well defined metabolic roles, the essentials of which varies depending on the physiological stage of animals [1-5]. Further, vitamins and trace minerals are the foundation of balanced pig nutrition: Proper supplementation of micronutrients in the diet is important for maintaining the health and growth performance of pigs, and for reducing unnecessary costs [5,6]. The National Research Council (NRC) estimates the recommended intake of dietary vitamins and trace minerals [6,7]. In the past few decades, many studies have been conducted to determine the vitamin requirements of pigs and these have been used by the NRC, but there has been relatively little change in the requirement estimates over that time frame $[6,8]$. The Feeding Standard of Swine also recommends the amounts of vitamins and trace minerals in the diet of China's pig producers [9]. In practice, most commercial diets are formulated with vitamin and trace mineral levels well above those recommended by the NRC and Feeding Standard of Swine, which take account of the potential variation and bioavailability of vitamins and 
trace minerals $[4,10]$, fluctuations in the daily feed intake of animals $[7,11]$, and degradation of vitamins due to transportation, storage, and processing $[12,13]$. In addition, two feeding guides (NRC and Feeding Standard of Swine) may not reflect greatly improved genetic selection and changes in management procedures of modern pig operations.

China is the world's largest pork producer and consumer. Farmers and companies in China produce more than 50 million metric tons of pork every year (National Bureau of Statistics of China). The high productivity of intensive farming in China requires the optimal levels of growth and reproduction performances. Vitamins and trace minerals may need to be adjusted to meet the increased strength of production, but much of the limited information available on this topic is outdated. The objective of this study was to collect information regarding added the amount of vitamin and trace mineral supplementation in pig diets across China's pig industry. We want to provide the information on a complete feed basis and include hand-added ingredients that have been used in formulations, to enable us to target more precise feeding during different phases of pig production.

\section{MATERIALS AND METHODS}

The procedures for this survey were approved by the Ministry of Agriculture and Rural Affairs Feed Industry Centre Committee (Beijing, China). Approval from the Animal Care and Use Committee was not obtained for this experiment because no animals were used. The survey information was collected in the digital spreadsheet (Excel; Microsoft 365, Redmond, WA, USA).

\section{Procedure}

The subjects of the investigation were pig producers within China. Most of the large producers in China were involved in this investigation, and the survey was completed from the period of January to December 2019. A total of 69 producers agreed to be involved with the investigation; the distribution and market share of these producers involved in the survey are presented in Figure 1. This survey sampled information from approximately $90 \%$ of China's pig herd. This pig production systems included most parts of mainland China. Questionnaires were distributed via E-mail and Wechat (Tencent Holdings Ltd., Shenzhen, China), which consisted of a survey covering major aspects of approximate weight breaks for feeding phases, the premix specifications (manufacturers of vitamins usually provide concentrated supplements known as premixes), inclusion rates of added vitamins and trace minerals, and response evaluation and outcomes.

Feeding phases division, vitamins, and trace minerals Different producers have different feeding stages and approximate dietary weight changes. However, the results were relatively consistent across a wide range of weights among all producers participating in this survey. The NRC is the most famous publication in pig nutrition and established the recommended requirement of vitamins and trace minerals for pigs, but for different body weight stages, the vitamins

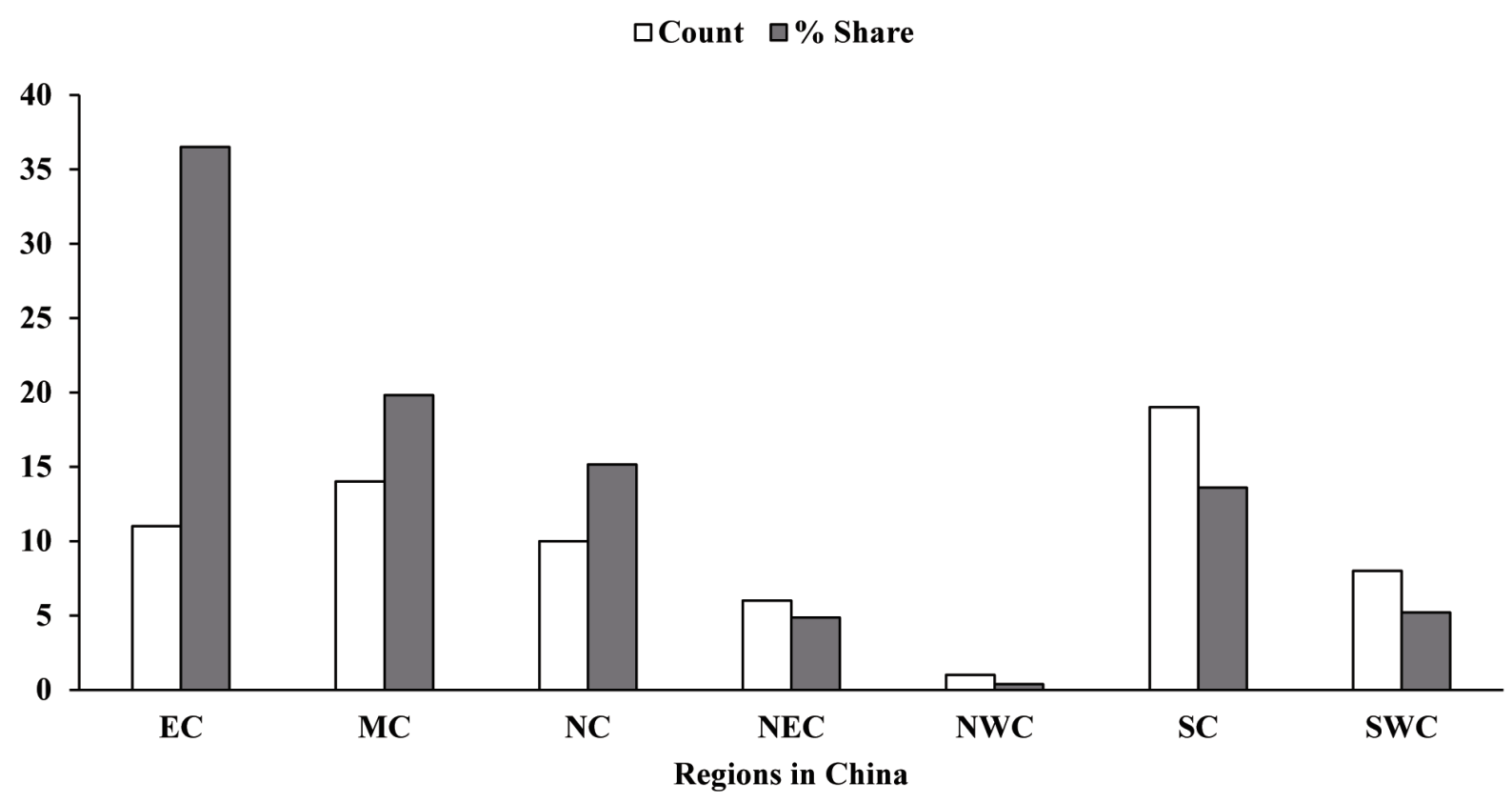

Figure 1. Distribution and market share of producers in China; EC, East China; MC, Middle China; NC, North China; NEC, Northeast China; NWC, Northwest China; SC, South China; SWC, Southwest China. 
and trace minerals required for pigs according to the NRC does not change much. In addition, we considered the specific status in China's animal husbandry, and the official recommendation of feeding standard in China [9] and application in production. The feeding phases were divided into five stages of pig production including creep, nursery, growing, finishing, and breeding phrases. The creep diets consisted of weanling to $8 \mathrm{~kg}$ body weight; the nursery diets consisted of early-phase (8 to $15 \mathrm{~kg}$ ) and later-phase (15 to $25 \mathrm{~kg}$ ) pigs; the growing diets consisted of 25 to $60 \mathrm{~kg}$ body weight animals; the finishing diets consisted of early-finishing (60 to $90 \mathrm{~kg}$ ) and late-finishing (90 kg to market) pigs; and breeding herd diets consisted of gilt development $(25 \mathrm{~kg}$ to breeding), gestation, lactation, and boar. Within each feeding phase, the vitamins and trace minerals were evaluated vitamin $A$, vitamin $D$, vitamin $E$, vitamin $K$, thiamine, riboflavin, vitamin $B_{6}$, vitamin $B_{12}$, pantothenic acid, niacin, folic acid, biotin, choline, copper, iron, manganese, zinc, selenium, and iodine.

\section{Statistical and analysis}

Basal information about producers was visualized using Microsoft Office 365 Excel (Microsoft Corporation, Redmond, WA, USA) and Adobe Illustrator 2020 (Adobe Inc., San Jose, CA, USA). Data were compiled, pooled, and reviewed by all members prior to publication. All values were determined by descriptive statistics using functions in the pivot tables in Excel (Microsoft 365, USA) and included average (AVERAGE), standard deviation (STDEV.S), median (MEDIAN), minimum (MIN), maximum (MAX), and the 25th and 75th percentiles (QUARTILE.EXC). The NRC provides estimates of the amounts of vitamins and trace minerals for various classes of pigs under average conditions. However, factors such as genetic variation, environment, availability of nutrients in feedstuffs, and other stressors may increase the concentration of some nutrients required for optimal reproduction performance. The vitamins and trace mineral estimation in China's Feeding Standard of Swine may be more specific for the pig industry in China. Thus, the average supplementation rate of each nutrient was calculated as two ratios to the suggested requirement as provided by the NRC [7] and China's Feeding Standard of Swine [9], respectively. This comparison was used to explore the status of vitamin and trace mineral utilization in China. We also calculated minimum and maximum inclusion rates as a proportion to these two requirement guides (data not shown). The NRC and China's Feeding Standard of Swine all provide total dietary vitamin and trace mineral requirements, while the results were presented that vitamins and trace minerals provided the following per kilogram of diet for each physiological stage of pigs.

\section{RESULTS}

\section{Creep stage}

The supplementation rates of vitamins and minerals in the creep diets are presented in Table 1 . The data was provided by 155 pig farms belonging to 37 producers. The average fat-soluble vitamin supplementation rate was 1.84 to 16.1 times higher than the estimated requirements published by the NRC and China's Feeding Standard. Vitamin D was supplemented at 16.1 times that of the NRC requirement estimate and China's Feeding Standard, and the supplementation of vitamin $\mathrm{D}$ had relatively high variation (standard deviation $[S D]=1,726.678$ ). The highest amount of variation ( $\mathrm{SD}=3,848.980$ ) occurred in vitamin A supplementation among producers. The average amount of supplemented vitamins $\mathrm{E}$ was close to their requirements (1.84 times), and the average supplemented vitamins $\mathrm{A}$ and $\mathrm{K}$ were 4.67 and 8.95 times that of NRC or China's Feeding Standard. Watersoluble vitamins were supplemented from 0.47 to 9.25 times for their NRC requirement estimates, and 0.75 to 9.25 times for the Feeding Standard. Vitamin $\mathrm{B}_{6}$, niacin, and choline was supplemented on average below the estimation of their requirements. Trace minerals were supplemented from 1.35 to 17.6 times over the NRC requirement estimate and China's Feeding Standard. Selenium was supplemented just over the requirement estimates ( 1.35 times). Supplemented iron and zinc were close to the NRC recommendation (2.58 and 4.25 times, respectively) and China's Feeding Standard (2.45 and 3.86 times, respectively). Copper, manganese, and iodine were supplemented well above the requirements at $13.7,17.6$, and 13.7 times over the recommendations of the NRC and China's Feeding Standard, respectively. The minimum vitamin and trace mineral contents were lower than NRC and China's Feeding Standard estimates, the average of their maximum supplementation was 48.7 and 48.9 times that of NRC and China's Feeding Standard, respectively.

\section{Nursery stage}

The early-nursery pig diet supplementation rates of vitamins and trace minerals are provided in Table 2. The 57 companies supplied feed to 327 pig farms, which were surveyed in this study. The average fat-soluble vitamin supplementation rate was 2.12 to 12.9 times higher than the NRC requirement estimates, and 3.08 to 14.1 times higher than Chinas Feeding Standard requirement. Vitamin D supplementation was 12.9 times higher than the NRC requirement estimate and 14.1 times higher than China's Feeding Standard. A high amount of variation ( $\mathrm{SD}=3,124.882)$ was observed in vitamin A supplementation across producers. The supplementation of vitamins $A, E$, and $K$ on average was close to the requirements, at 4.63, 2.12, and 6.91 times higher than the NRC; at 5.66, 3.08, and 6.91 times higher than China's Feeding Stan- 
Table 1. The composition of supplemented vitamins and trace minerals in creep diets (weanling to $8 \mathrm{~kg}$ )

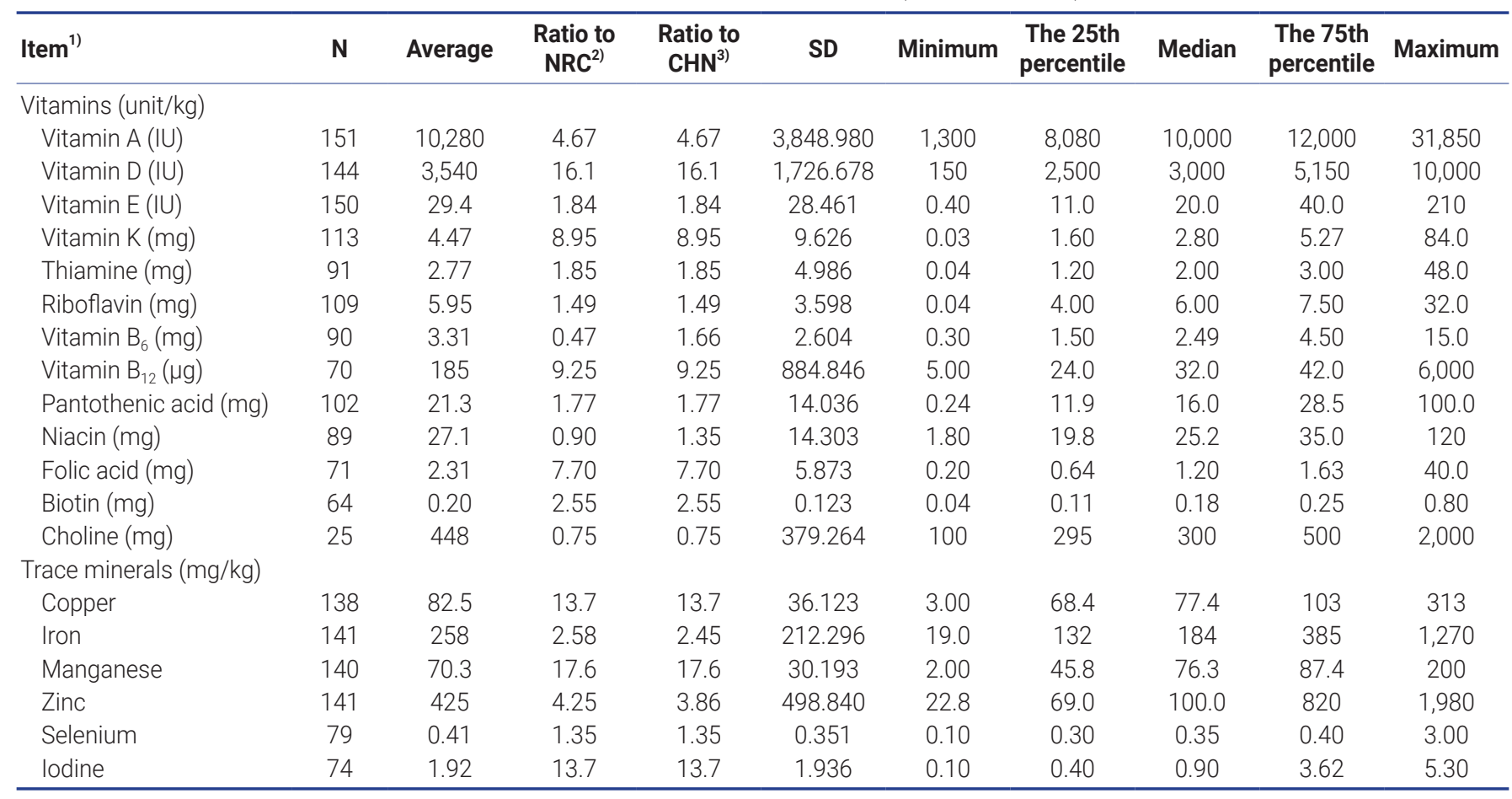

The $\mathrm{N}$ represents the number of farms; SD, standard deviation.

1) All reported values are on an as-fed basis and represent vitamins and trace minerals provided the following per kilogram of diet for pigs.

${ }^{2)}$ Values represent average supplementation rates as a proportion to dietary vitamin and trace mineral requirements recommendation from the NRC [7].

${ }^{3)}$ Values represent average supplementation rates as a proportion to dietary vitamin and trace mineral requirements recommendation from the China's

Feeding Standard of Swine [9].

dard, respectively. Water-soluble vitamin supplementation was from 0.42 to 7.95 times higher than the NRC requirement estimate, and 0.69 to 7.95 times higher than China's Feeding Standard. The average vitamin $\mathrm{B}_{6}$ and niacin supplementation were below the NRC requirement by 0.42 and 0.88 times, respectively, but at their requirement estimate in China's Feeding Standard by 1.94 and 1.76 times, respectively. Choline supplementation was 0.69 times lower than the NRC and China's Feeding Standard. Trace minerals supplementation was from 1.23 to 15.7 times higher than the NRC requirement estimate and China's Feeding Standard. Selenium supplementation met the requirements. Iron, zinc, and iodine were added at levels close their requirements $(2.44,5.34$, and 8.91 times higher than the NRC requirement, respectively, and 2.32, 4.86, and 8.91 higher than China's Feeding Standard, respectively), and copper and manganese were supplemented well above their requirement estimate, at 12.8 and 15.7 times that of the two feeding recommendations, respectively. The minimum vitamin and trace mineral were supplementation fell below two requirement estimates, but the average of their maximum supplementation was 52.5 and 53.9 times higher than the NRC and China's Feeding Standard requirements, respectively.

The supplementation rates of vitamins and trace minerals for later-nursery pig diet are reported in Table 3. A total of 64 companies were surveyed, which supplied feed to 502 nursery pig farms. The average fat-soluble vitamin supplementation rate was 2.38 to 12.8 times higher than the NRC estimations, and 2.38 to 15.1 times higher than China's Feeding Standard. Vitamin D supplementation was 12.8 times higher than the NRC requirement and 15.1 times higher than China's Feeding Standard. There was substantial variation $(\mathrm{SD}=3,103.867)$ noticed in vitamin A supplementation in this stage. The average added vitamins $\mathrm{A}, \mathrm{E}$, and $\mathrm{K}$ were close to the requirements. Water-soluble vitamins were supplemented from 0.72 to 7.64 times their NRC requirement estimate, and 0.83 to 7.64 times China's Feeding Standard. The average supplementation rates of vitamin $\mathrm{B}_{6}$, niacin, and choline were lower than NRC values (by $0.82,0.77$, and 0.72 times), although only the amount of choline in diets was lower than Chinas Feeding Standard requirement ( 0.83 times). Trace minerals supplementation was from 1.19 to 20.6 times that of NRC requirement estimate, and from 1.11 to 20.6 times that of China's Feeding Standard. Iron, zinc, and selenium were supplemented at their required levels, but copper, manganese, and iodine were supplemented well above their requirement estimate $(15.4,20.6$, and 11.2 times that of NRC requirement, respectively; 17.1, 20.6, and 11.2 times that of 
Table 2. The composition of supplemented vitamins and trace minerals in early nursery diets (8 to $15 \mathrm{~kg}$ )

\begin{tabular}{|c|c|c|c|c|c|c|c|c|c|c|}
\hline Item ${ }^{1)}$ & $\mathbf{N}$ & Average & $\begin{array}{l}\text { Ratio to } \\
\text { NRC }^{2)}\end{array}$ & $\begin{array}{l}\text { Ratio to } \\
\text { CHN }^{3)}\end{array}$ & SD & Minimum & $\begin{array}{l}\text { The 25th } \\
\text { percentile }\end{array}$ & Median & $\begin{array}{l}\text { The 75th } \\
\text { percentile }\end{array}$ & Maximum \\
\hline \multicolumn{11}{|l|}{ Vitamins (unit/kg) } \\
\hline Vitamin A (IU) & 312 & 10,186 & 4.63 & 5.66 & $3,124.882$ & 700 & 8,750 & 10,000 & 11,750 & 31,850 \\
\hline Vitamin D (IU) & 303 & 2,828 & 12.9 & 14.1 & $1,239.169$ & 150 & 2,200 & 2,900 & 3,200 & 10,000 \\
\hline Vitamin E (IU) & 310 & 33.9 & 2.12 & 3.08 & 31.953 & 0.40 & 15.2 & 22.0 & 41.0 & 240 \\
\hline Vitamin K (mg) & 263 & 3.46 & 6.91 & 6.91 & 6.402 & 0.03 & 2.00 & 2.75 & 3.75 & 84.0 \\
\hline Vitamin $B_{6}(\mathrm{mg})$ & 224 & 2.91 & 0.42 & 1.94 & 2.317 & 0.02 & 1.50 & 2.30 & 4.00 & 20.0 \\
\hline Vitamin $\mathrm{B}_{12}(\mu \mathrm{g})$ & 140 & 106 & 6.08 & 6.08 & 628.468 & 1.50 & 18.3 & 29.9 & 38.4 & 6,000 \\
\hline Pantothenic acid (mg) & 236 & 19.3 & 1.93 & 1.93 & 11.839 & 0.18 & 10.5 & 16.0 & 24.9 & 100.0 \\
\hline Niacin $(\mathrm{mg})$ & 218 & 26.4 & 0.88 & 1.76 & 14.766 & 0.20 & 17.2 & 25.0 & 36.0 & 120 \\
\hline Folic acid (mg) & 123 & 2.38 & 7.95 & 7.95 & 6.099 & 0.03 & 0.58 & 0.90 & 1.80 & 40.0 \\
\hline Iron & 290 & 244 & 2.44 & 2.32 & 155.763 & 0.13 & 130 & 200 & 371 & 1,270 \\
\hline Manganese & 285 & 62.6 & 15.7 & 15.7 & 27.680 & 0.03 & 40.0 & 64.0 & 80.0 & 200 \\
\hline Zinc & 286 & 534 & 5.34 & 4.86 & 494.257 & 0.12 & 80.0 & 133.3 & 913 & 1,980 \\
\hline Selenium & 164 & 0.37 & 1.23 & 1.23 & 0.315 & 0.09 & 0.24 & 0.32 & 0.39 & 3.00 \\
\hline lodine & 159 & 1.25 & 8.91 & 8.91 & 1.410 & 0.10 & 0.40 & 0.60 & 1.28 & 5.20 \\
\hline
\end{tabular}

The $\mathrm{N}$ represents the number of farms; SD, standard deviation.

1) All reported values are on an as-fed basis and represent vitamins and trace minerals provided the following per kilogram of diet for pigs.

${ }^{2)}$ Values represent average supplementation rates as a proportion to dietary vitamin and trace mineral requirements recommendation from the NRC [7]

${ }^{3)}$ Values represent average supplementation rates as a proportion to dietary vitamin and trace mineral requirements recommendation from the China's

Feeding Standard of Swine [9].

Table 3. The composition of supplemented vitamins and trace minerals in late nursery diets (15 to $25 \mathrm{~kg}$ )

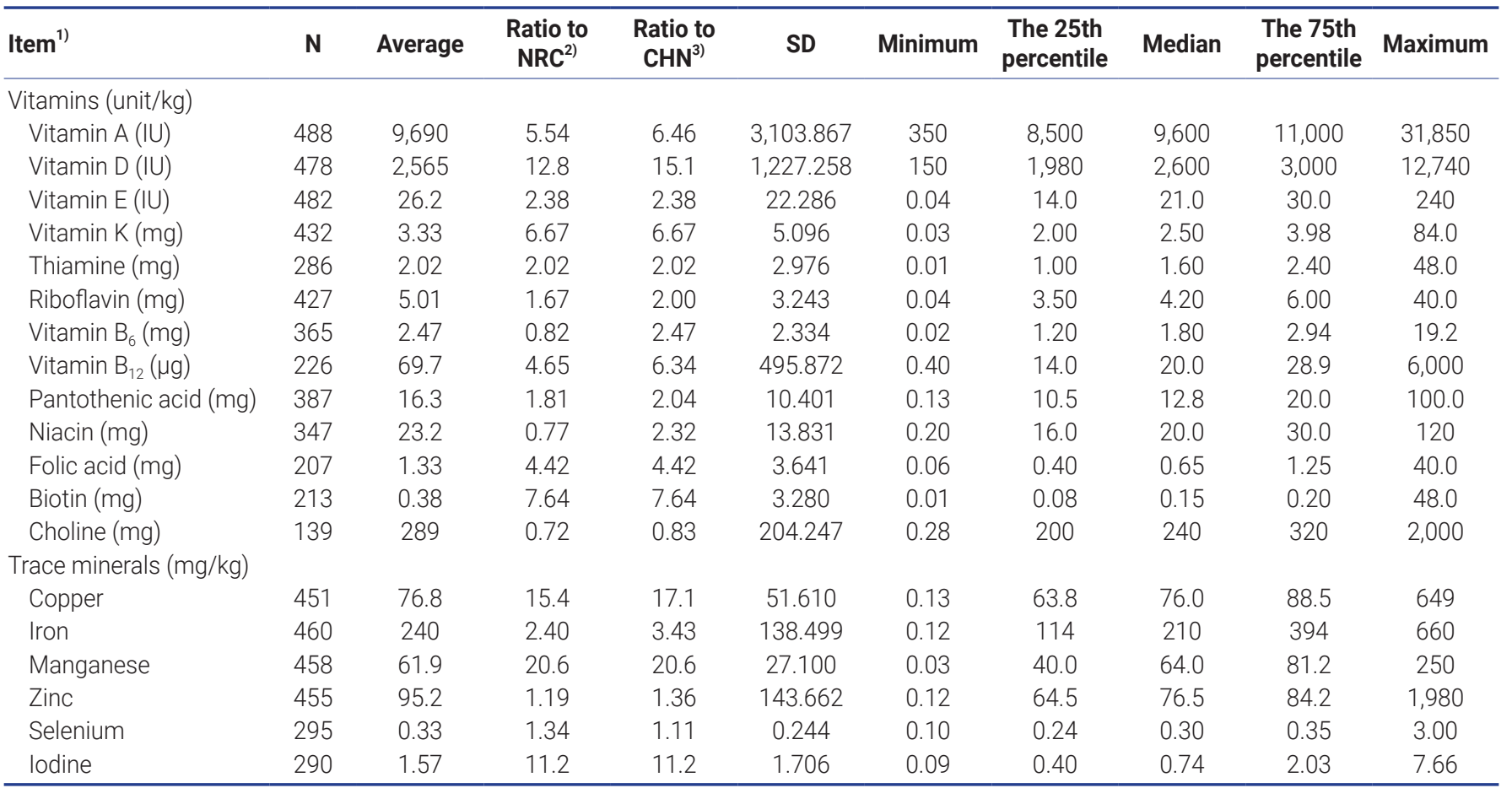

The $\mathrm{N}$ represents the number of farms; SD, standard deviation.

1) All reported values are on an as-fed basis and represent vitamins and trace minerals provided the following per kilogram of diet for pigs.

2) Values represent average supplementation rates as a proportion to dietary vitamin and trace mineral requirements recommendation from the NRC [7].

3) Values represent average supplementation rates as a proportion to dietary vitamin and trace mineral requirements recommendation from the China's

Feeding Standard of Swine [9]. 
China's Feeding Standard, respectively). The minimum vitamin and trace mineral supplementation levels were lower than NRC and China's Feeding Standard estimates, while the average of their maximum supplementation was 113.9 and 124.6 times that of NRC and China's Feeding Standard, respectively.

\section{Growing stage}

The supplementation rates of vitamins and trace minerals provided by 444 pig farms from 69 producers are presented in Table 4 . The average fat-soluble vitamin supplementation rates were from 1.83 to 14.3 times over their NRC requirement estimate, and 1.83 to 13.4 times over China's Feeding Standard. Among all vitamin categories, vitamin D has the highest ratio to nutrition estimates. The highest variation ( $\mathrm{SD}=2,295.752)$ was reported for vitamin A supplementation among these producers. Vitamin E supplementation was on average close to the requirement estimates (1.83 times). Average supplementation rates for vitamins $\mathrm{A}$ and $\mathrm{K}$ were 3.80 and 5.10 times higher than the NRC estimates, and 3.53 and 5.10 times higher than China's Feeding Standard. The supplemented water-soluble vitamins basically met growing pigs' requirements in NRC and China's Feeding Standard. Water-soluble vitamins were supplemented from 0.56 to 2.48 times that of their NRC requirement estimates, and 0.88 to
2.48 times that of China's Feeding Standard. The average supplementation rate of niacin was lower than the NRC estimate ( 0.56 times), and the average supplemented choline was lower than NRC (0.88 times) and China's Feeding Standard (0.88 times). Trace minerals were supplemented from 1.02 to 28.5 times NRC estimate and China's Feeding Standard. Zinc and selenium were supplemented according to requirements, and the added copper and iron were close to the requirements of the NRC and China's Feeding Standard. Manganese and iodine were supplemented well over the requirements, at 28.5 and 11.6 times that of NRC or China's Feeding Standard, respectively. The minimum vitamin and trace mineral levels were below the requirements for two estimates, while the average of their maximum supplementation was 25.1 and 25.9 times that of NRC and China's Feeding Standard, respectively.

\section{Early-finishing stage}

The vitamin and trace mineral supplementation rates in earlyfinishing diet (60 to $90 \mathrm{~kg}$ ) are shown in Table 5. There were 63 producers surveyed for this feeding stage. These producers supplied early-finishing feed to 417 pig farms. The average fat-soluble vitamin supplementation rate was 2.09 to 13.7 times that of the NRC requirement estimate and China's Feeding Standard. Vitamin D was supplemented at 13.7 times

Table 4. The composition of supplemented vitamins and trace minerals in growing diets (25 to $60 \mathrm{~kg})$

\begin{tabular}{|c|c|c|c|c|c|c|c|c|c|c|}
\hline (tem ${ }^{1)}$ & $\mathbf{N}$ & Average & $\begin{array}{c}\text { Ratio to } \\
\text { NRC }^{2)}\end{array}$ & $\begin{array}{l}\text { Ratio to } \\
\mathrm{CHN}^{3)}\end{array}$ & SD & Minimum & $\begin{array}{l}\text { The } 25 \text { th } \\
\text { percentile }\end{array}$ & Median & $\begin{array}{l}\text { The } 75 \text { th } \\
\text { percentile }\end{array}$ & Maximum \\
\hline \multicolumn{11}{|l|}{ Vitamins (unit/kg) } \\
\hline Vitamin A (IU) & 428 & 4,946 & 3.80 & 3.53 & $2,295.752$ & 1,300 & 4,050 & 4,695 & 5,250 & 31,000 \\
\hline Vitamin D (IU) & 424 & 2,145 & 14.3 & 13.4 & $1,071.845$ & 0.29 & 1,480 & 2,400 & 2,750 & 11,600 \\
\hline Vitamin E (IU) & 427 & 20.1 & 1.83 & 1.83 & 24.089 & 0.40 & 10.4 & 15.6 & 20.8 & 240 \\
\hline Vitamin K (mg) & 379 & 2.55 & 5.10 & 5.10 & 1.833 & 0.03 & 1.20 & 1.65 & 4.10 & 8.80 \\
\hline Thiamine (mg) & 233 & 1.20 & 1.20 & 1.20 & 0.681 & 0.004 & 0.87 & 1.04 & 1.58 & 6.60 \\
\hline Riboflavin (mg) & 378 & 3.42 & 1.37 & 1.71 & 1.654 & 0.04 & 2.40 & 3.00 & 4.02 & 19.8 \\
\hline Vitamin $B_{6}(\mathrm{mg})$ & 297 & 1.55 & 1.55 & 1.55 & 1.542 & 0.02 & 0.78 & 1.00 & 2.00 & 16.0 \\
\hline Vitamin $B_{12}(\mu \mathrm{g})$ & 185 & 14.8 & 1.48 & 1.85 & 8.394 & 2.40 & 10.0 & 15.0 & 19.2 & 96.0 \\
\hline Pantothenic acid (mg) & 342 & 12.4 & 1.54 & 1.65 & 8.119 & 0.10 & 7.4 & 10.0 & 16.0 & 97.0 \\
\hline Niacin (mg) & 299 & 16.7 & 0.56 & 1.97 & 12.697 & 0.06 & 10.0 & 17.0 & 20.0 & 200 \\
\hline Folic acid (mg) & 159 & 0.74 & 2.48 & 2.48 & 1.858 & 0.08 & 0.30 & 0.40 & 0.64 & 20.0 \\
\hline Biotin (mg) & 146 & 0.12 & 2.33 & 2.33 & 0.077 & 0.01 & 0.07 & 0.09 & 0.15 & 0.48 \\
\hline Choline (mg) & 119 & 263 & 0.88 & 0.88 & 235.787 & 20.0 & 160 & 200 & 300 & 2,000 \\
\hline \multicolumn{11}{|l|}{ Trace minerals (mg/kg) } \\
\hline Copper & 422 & 21.1 & 5.28 & 5.28 & 24.748 & 3.00 & 14.0 & 15.5 & 17.5 & 200 \\
\hline Iron & 432 & 230 & 3.83 & 3.83 & 134.905 & 0.13 & 111 & 184 & 380 & 638 \\
\hline Manganese & 425 & 57.0 & 28.5 & 28.5 & 24.278 & 0.03 & 35.0 & 60.0 & 77.5 & 137 \\
\hline Zinc & 423 & 61.0 & 1.02 & 1.02 & 26.212 & 0.12 & 50.0 & 58.4 & 63.6 & 275 \\
\hline Selenium & 282 & 0.32 & 1.59 & 1.27 & 0.181 & 0.10 & 0.24 & 0.30 & 0.33 & 1.30 \\
\hline Iodine & 278 & 1.63 & 11.6 & 11.6 & 1.794 & 0.10 & 0.38 & 0.78 & 2.10 & 7.65 \\
\hline
\end{tabular}

The $\mathrm{N}$ represents the number of farms; SD, standard deviation.

1) All reported values are on an as-fed basis and represent vitamins and trace minerals provided the following per kilogram of diet for pigs.

2) Values represent average supplementation rates as a proportion to dietary vitamin and trace mineral requirements recommendation from the NRC [7]

3) Values represent average supplementation rates as a proportion to dietary vitamin and trace mineral requirements recommendation from the China's

Feeding Standard of Swine [9]. 
Table 5. The composition of supplemented vitamins and trace minerals in early-finishing diets (60 to $90 \mathrm{~kg}$ )

\begin{tabular}{|c|c|c|c|c|c|c|c|c|c|c|}
\hline Item ${ }^{1)}$ & $\mathbf{N}$ & Average & $\begin{array}{l}\text { Ratio to } \\
\text { NRC }^{2)}\end{array}$ & $\begin{array}{c}\text { Ratio to } \\
\text { CHN }^{3)}\end{array}$ & SD & Minimum & $\begin{array}{l}\text { The } 25 \text { th } \\
\text { percentile }\end{array}$ & Median & $\begin{array}{l}\text { The 75th } \\
\text { percentile }\end{array}$ & Maximum \\
\hline \multicolumn{11}{|l|}{ Vitamins (unit/kg) } \\
\hline Vitamin A (IU) & 405 & 4,656 & 3.58 & 3.58 & $1,775.468$ & 1,300 & 3,930 & 4,600 & 5,073 & 22,400 \\
\hline Vitamin E (IU) & 402 & 23.0 & 2.09 & 2.09 & 30.138 & 0.80 & 10.0 & 12.6 & 22.1 & 240 \\
\hline Vitamin K (mg) & 355 & 4.94 & 9.87 & 9.87 & 29.978 & 0.20 & 1.05 & 1.60 & 4.16 & 400 \\
\hline Vitamin $\mathrm{B}_{6}(\mathrm{mg})$ & 277 & 1.54 & 1.54 & 1.54 & 1.989 & 0.02 & 0.64 & 1.00 & 1.92 & 16.0 \\
\hline Vitamin $B_{12}(\mu \mathrm{g})$ & 174 & 47.7 & 9.54 & 7.95 & 319.338 & 0.01 & 8.00 & 12.0 & 18.3 & 3,000 \\
\hline Pantothenic acid (mg) & 301 & 10.7 & 1.53 & 1.53 & 5.972 & 0.10 & 5.60 & 8.55 & 16.0 & 36.0 \\
\hline Niacin $(\mathrm{mg})$ & 263 & 15.0 & 0.50 & 2.00 & 7.455 & 0.48 & 9.60 & 15.0 & 20.0 & 45.0 \\
\hline Folic acid (mg) & 144 & 0.95 & 3.16 & 3.16 & 2.934 & 0.08 & 0.22 & 0.34 & 0.60 & 20.0 \\
\hline Iron & 400 & 228 & 4.56 & 4.56 & 142.305 & 0.13 & 99.1 & 199 & 389 & 638 \\
\hline Manganese & 395 & 58.3 & 29.1 & 29.1 & 28.666 & 0.03 & 33.0 & 60.0 & 79.0 & 334 \\
\hline Zinc & 394 & 61.8 & 1.24 & 1.24 & 54.888 & 0.12 & 48.0 & 58.8 & 62.3 & 1,075 \\
\hline Selenium & 274 & 0.37 & 2.46 & 1.47 & 1.115 & 0.03 & 0.24 & 0.30 & 0.32 & 18.6 \\
\hline lodine & 258 & 1.61 & 11.5 & 11.5 & 1.814 & 0.03 & 0.38 & 0.78 & 1.77 & 7.67 \\
\hline
\end{tabular}

The $\mathrm{N}$ represents the number of farms; SD, standard deviation.

1) All reported values are on an as-fed basis and represent vitamins and trace minerals provided the following per kilogram of diet for pigs.

2) Values represent average supplementation rates as a proportion to dietary vitamin and trace mineral requirements recommendation from the NRC [7].

${ }^{3)}$ Values represent average supplementation rates as a proportion to dietary vitamin and trace mineral requirements recommendation from the China's

Feeding Standard of Swine [9].

over the NRC requirement estimate and China’s Feeding Standard. The highest variation $(\mathrm{SD}=1,775.468)$ of vitamin A supplementation was observed at this stage. The average supplementation of vitamins $\mathrm{A}$ and $\mathrm{E}$ were close to the requirements (3.58 and 2.09 times that of NRC or China's Feeding Standard, respectively). Water-soluble vitamins were supplemented from 0.50 to 9.54 times their NRC requirement estimate, and 0.63 to 7.95 times China's Feeding Standard. The average supplementation rate of niacin was lower than NRC estimate, and the average supplemented concentration of choline was lower than NRC and China's Feeding Standard requirements. Trace minerals supplementation was from 1.24 to 29.1 times higher than the NRC requirement estimate and China's Feeding Standard requirements. Iron was added at levels 4.56 times higher than the NRC and Chinass Feeding Standard requirements. Zinc and selenium were supplemented on average at their requirement estimate, while copper was supplemented at levels 5.26 times greater than their requirement estimation. Manganese and iodine were supplemented well above their requirement estimate, at 29.1 and 11.5 times that of the NRC requirement estimate and China's Feeding Standard. The minimum values of vitamins $\mathrm{A}$ and $\mathrm{D}$ were supplemented at NRC requirement estimate and China's Feeding Standard, but the minimum value of the other vitamins or trace minerals were supplemented below the two estimations. However, the average of their maximum supplementation was 116.9 and 109.3 times higher than the NRC and China's Feeding Standard requirements, respectively.

\section{Later-finishing stage}

The inclusion rates of vitamins and trace minerals in the later-finishing diet (90 kg to market body weight) are reported in Table 6 . These findings were provided by 435 pig farms from 61 producers. The fat-soluble vitamin supplementation rate was 2.17 to 13.6 times that of their NRC requirement estimates and China's Feeding Standard, respectively. Vitamin D supplementation was 13.4 times that of the NRC requirement estimate and China's Feeding Standard. Vitamin K supplementation was 13.6 times over the NRC requirement estimate and China's Feeding Standard. A high amount of variation ( $S D=1,772.387$ ) was observed in vitamin A supplementation among producers. Vitamins $\mathrm{A}$ and $\mathrm{E}$ were supplemented on average at their requirement estimates. Most water-soluble vitamins were fundamentally supplemented to meet finishing pig's requirements according to the NRC and China's Feeding Standard, except for niacin and choline. Niacin supplementation was 0.51 times 
Table 6. The composition of supplemented vitamins and trace minerals in late finishing diets (90 kg to market)

\begin{tabular}{|c|c|c|c|c|c|c|c|c|c|c|}
\hline Item ${ }^{1)}$ & $\mathbf{N}$ & Average & $\begin{array}{l}\text { Ratio to } \\
\text { NRC }^{2)}\end{array}$ & $\begin{array}{l}\text { Ratio to } \\
\text { CHN }^{3)}\end{array}$ & SD & Minimum & $\begin{array}{l}\text { The 25th } \\
\text { percentile }\end{array}$ & Median & $\begin{array}{l}\text { The 75th } \\
\text { percentile }\end{array}$ & Maximum \\
\hline \multicolumn{11}{|l|}{ Vitamins (unit/kg) } \\
\hline Vitamin A (IU) & 420 & 4,826 & 3.71 & 3.71 & $1,772.387$ & 1,300 & 4,000 & 4,700 & 5,250 & 22,400 \\
\hline Vitamin D (IU) & 423 & 2,005 & 13.4 & 13.4 & 914.246 & 150 & 1,300 & 2,160 & 2,690 & 6,000 \\
\hline Vitamin E (IU) & 419 & 23.9 & 2.17 & 2.17 & 31.285 & 0.80 & 10.0 & 12.8 & 24.0 & 205 \\
\hline Vitamin K (mg) & 375 & 6.79 & 13.6 & 13.6 & 41.169 & 0.20 & 1.00 & 1.60 & 3.80 & 400 \\
\hline Vitamin $B_{6}(\mathrm{mg})$ & 290 & 1.54 & 1.54 & 1.54 & 1.724 & 0.02 & 0.64 & 1.00 & 2.00 & 16.0 \\
\hline Vitamin $B_{12}(\mu \mathrm{g})$ & 194 & 29.1 & 5.82 & 4.85 & 214.499 & 0.01 & 9.15 & 12.2 & 19.1 & 3,000 \\
\hline Pantothenic acid (mg) & 328 & 10.8 & 1.54 & 1.54 & 5.931 & 0.10 & 5.60 & 8.63 & 16.0 & 36.0 \\
\hline Niacin (mg) & 286 & 15.3 & 0.51 & 2.04 & 7.305 & 0.48 & 10.0 & 15.0 & 19.6 & 45.0 \\
\hline Folic acid (mg) & 155 & 0.77 & 2.58 & 2.58 & 2.129 & 0.08 & 0.23 & 0.36 & 0.65 & 16.0 \\
\hline Iron & 394 & 229 & 5.72 & 4.58 & 139.995 & 0.13 & 101 & 200 & 383 & 638 \\
\hline Manganese & 388 & 57.3 & 28.6 & 28.6 & 25.087 & 0.03 & 33.3 & 60.0 & 80.0 & 136 \\
\hline Zinc & 388 & 62.5 & 1.25 & 1.25 & 55.358 & 0.12 & 48.9 & 60.0 & 63.3 & 1,075 \\
\hline Selenium & 256 & 0.30 & 2.02 & 1.21 & 0.150 & 0.03 & 0.24 & 0.30 & 0.33 & 1.20 \\
\hline lodine & 244 & 1.48 & 10.6 & 10.6 & 1.723 & 0.03 & 0.38 & 0.75 & 1.38 & 7.67 \\
\hline
\end{tabular}

The $\mathrm{N}$ represents the number of farms; SD, standard deviation.

1) All reported values are on an as-fed basis and represent vitamins and trace minerals provided the following per kilogram of diet for pigs.

2) Values represent average supplementation rates as a proportion to dietary vitamin and trace mineral requirements recommendation from the $\mathrm{NRC}$ [7]

3) Values represent average supplementation rates as a proportion to dietary vitamin and trace mineral requirements recommendation from the China's

Feeding Standard of Swine [9].

that of the NRC requirement estimate, and choline supplementation was 0.66 times that of the NRC and Chinas Feeding Standard requirements. Trace minerals were supplemented at levels from 1.25 to 28.6 times the NRC requirement estimate and China's Feeding Standard. Zinc and selenium were supplemented to meet the requirement estimates, while copper and iron supplementations were approximately five times over the requirements. Manganese and iodine were supplemented well above their requirement estimate, at 28.6 and 10.6 times that of the NRC and Chinas Feeding Standard, respectively. The minimum supplementation of vitamins $\mathrm{A}$ and D were at NRC requirement estimate and China's Feeding Standard levels, and the average of their maximum supplementation was 101.5 and 95.6 times that of NRC and China's Feeding Standard, respectively.

\section{Gilt-development stage}

The added vitamin and trace mineral concentrations in giltdevelopment diets were described by 157 farms which are affiliated with 43 producers (Table 7). The average fat-soluble vitamin supplementation rates were 4.14 to 16.7 times that of their NRC requirement estimate, and 4.14 to 14.8 times that of China's Feeding Standard. Vitamin D was supplemented at 16.7 times that of the NRC requirement estimate and 14.8 times that of Chinas Feeding Standard. The supplementation of vitamin A varied ( $\mathrm{SD}=2,952.290$ ) from producer to producer. The average supplementation rates of vitamins $\mathrm{A}$ and $\mathrm{E}$ were at the requirement estimate. Most water-soluble vitamins were numerically similar with a pig's requirements according to the NRC and China's Feeding Standard, except for niacin, folic acid, and biotin. The added niacin in gilt-development diets was 0.75 times that of the NRC requirement estimate, and folic acid and biotin were supplemented at 7.80 and 11.6 times of their estimated values in NRC and China's Feeding Standard, respectively. Trace minerals were supplemented from 1.15 to 32.4 times that of the NRC requirement estimate, and 0.99 to 21.6 times of China's Feeding Standard. Copper, iron, zinc, and selenium were supplemented at the required concentration, and manganese and iodine were supplemented above the required concentration, at 32.4 and 10.3 times that of the NRC guidance and at 21.6 and 10.3 times that of China's Feeding Standard, respectively. The minimum supplementation of vitamins A and D were at the NRC requirement concentration, while other vitamins and trace minerals were supplemented well below the two estimations of their requirements. The average of their maximum supplementation was 35.2 and 32.7 times that of NRC and China's Feeding Standard, respectively. 
Table 7. The composition of supplemented vitamins and trace minerals in gilt-development diets

\begin{tabular}{|c|c|c|c|c|c|c|c|c|c|c|}
\hline Item ${ }^{1)}$ & $\mathbf{N}$ & Average & $\begin{array}{l}\text { Ratio to } \\
\text { NRC }^{2)}\end{array}$ & $\begin{array}{l}\text { Ratio to } \\
\text { CHN }^{3)}\end{array}$ & SD & Minimum & $\begin{array}{l}\text { The 25th } \\
\text { percentile }\end{array}$ & Median & $\begin{array}{l}\text { The 75th } \\
\text { percentile }\end{array}$ & Maximum \\
\hline \multicolumn{11}{|l|}{ Vitamins (unit/kg) } \\
\hline Vitamin A (IU) & 151 & 6,640 & 5.11 & 4.43 & $2,952.290$ & 1,300 & 4,800 & 6,650 & 7,800 & 27,660 \\
\hline Vitamin D (IU) & 151 & 2,512 & 16.7 & 14.8 & $1,494.768$ & 150 & 1,900 & 2,600 & 3,000 & 17,750 \\
\hline Vitamin E (IU) & 151 & 45.5 & 4.14 & 4.14 & 38.031 & 2.50 & 20.0 & 42.0 & 50.0 & 240 \\
\hline Vitamin K (mg) & 131 & 3.01 & 6.02 & 6.02 & 1.793 & 0.43 & 2.00 & 2.40 & 4.55 & 7.60 \\
\hline Vitamin $B_{6}(\mathrm{mg})$ & 115 & 2.57 & 2.57 & 2.57 & 2.273 & 0.39 & 1.20 & 2.44 & 3.20 & 18.0 \\
\hline Vitamin $\mathrm{B}_{12}(\mu \mathrm{g})$ & 46 & 14.7 & 1.47 & 1.33 & 6.856 & 5.00 & 8.30 & 16.0 & 20.0 & 31.5 \\
\hline Pantothenic acid (mg) & 113 & 16.1 & 2.01 & 2.01 & 7.820 & 0.22 & 10.1 & 14.5 & 20.0 & 45.0 \\
\hline Niacin $(\mathrm{mg})$ & 96 & 22.6 & 0.75 & 2.26 & 10.951 & 2.00 & 14.6 & 22.0 & 31.5 & 50.0 \\
\hline Folic acid (mg) & 49 & 2.34 & 7.80 & 7.80 & 4.117 & 0.06 & 0.32 & 0.75 & 3.75 & 27.0 \\
\hline Iron & 154 & 236 & 3.93 & 3.37 & 128.045 & 0.13 & 116 & 230 & 382 & 465 \\
\hline Manganese & 152 & 64.8 & 32.4 & 21.6 & 24.034 & 0.04 & 41.3 & 69.0 & 85.0 & 103 \\
\hline Zinc & 152 & 69.3 & 1.15 & 0.99 & 13.894 & 30.0 & 58.4 & 70.0 & 78.0 & 123 \\
\hline Selenium & 107 & 0.36 & 1.79 & 1.20 & 0.263 & 0.10 & 0.24 & 0.30 & 0.35 & 1.50 \\
\hline lodine & 115 & 1.44 & 10.3 & 10.3 & 1.692 & 0.10 & 0.40 & 0.60 & 1.20 & 5.18 \\
\hline
\end{tabular}

The $\mathrm{N}$ represents the number of farms; SD, standard deviation.

1) All reported values are on an as-fed basis and represent vitamins and trace minerals provided the following per kilogram of diet for pigs.

${ }^{2)}$ Values represent average supplementation rates as a proportion to dietary vitamin and trace mineral requirements recommendation from the NRC [7].

${ }^{3)}$ Values represent average supplementation rates as a proportion to dietary vitamin and trace mineral requirements recommendation from the China's

Feeding Standard of Swine [9].

\section{Gestation, lactation, and boar}

The supplementation rates of vitamin and trace minerals in gestating sow diets are displayed in Table 8. The data were provided by 391 farms which were affiliated with 60 producers. The average fat-soluble vitamin supplementation rates were 1.04 to 8.86 times that of their NRC requirement estimates, and 1.14 to 13.6 times that of China's Feeding Standard. Vitamin $\mathrm{K}_{3}$ was supplemented at 8.83 times that of the two requirement estimates. Vitamin $\mathrm{D}_{3}$ was supplemented at 13.6 times that of China's Feeding Standard. The variation of supplemental vitamin A was higher than other ingredients $(\mathrm{SD}=2,119.621)$. Water-soluble vitamins were supplemented from 0.32 to 3.57 times their NRC requirement estimate, and 0.34 to 3.83 times China's Feeding Standard. The added contents of water-soluble vitamins were similar with the two requirement estimates, but choline was supplemented at 0.32 and 0.34 times of the NRC and China's Feeding Standard requirements, respectively. Trace minerals were supplemented from 0.72 to 9.40 times that of the NRC requirement estimate, and 1.61 to 10.1 times that of China's Feeding Standard. Iodine was supplemented at levels well above the requirement estimates, at 9.40 times that of the NRC guidance and 10.1 times that of China's Feeding Standard. The minimum supplementation values of vitamins and trace minerals were well below the two requirement estimates. The average of their maximum supplementation was 66.5 and 73.3 times that of NRC and China's Feeding Standard, respectively.

The added vitamin and trace minerals in the lactation diet are shown in Table 9. This information was provided by 387 pig farms from 59 producers. The average fat-soluble vitamin supplementation rates were 1.05 to 8.95 times that of their NRC requirement estimates, and 1.03 to 11.9 times that of China's Feeding Standard. Vitamin K was supplemented at 8.95 times that of both requirement estimations. Vitamin D was supplemented at 11.9 times that of China's Feeding Standard. The highest variation was observed within vitamin A supplementation ( $\mathrm{SD}=1,693.699)$. Water-soluble vitamins were supplemented from 0.35 to 5.29 times their NRC requirement estimates and China's Feeding Standard. The average supplementation rate of choline was at 0.35 times that of NRC requirement and China's Feeding Standard, respectively. Trace minerals were supplemented from 0.72 to 10.3 times that of the NRC requirement estimate, and 1.40 to 10.3 times that of China's Feeding Standard. Copper, iron, manganese, zinc, and selenium were supplemented at their required levels, while iodine was supplemented 10.3 times over the requirements outlined by the NRC and China's 
Table 8. The composition of supplemented vitamins and trace minerals in gestation diets

\begin{tabular}{|c|c|c|c|c|c|c|c|c|c|c|}
\hline Item ${ }^{1)}$ & $\mathbf{N}$ & Average & $\begin{array}{c}\text { Ratio to } \\
\text { NRC }^{2)}\end{array}$ & $\begin{array}{c}\text { Ratio to } \\
\mathrm{CHN}^{3)}\end{array}$ & SD & Minimum & $\begin{array}{l}\text { The 25th } \\
\text { percentile }\end{array}$ & Median & $\begin{array}{l}\text { The 75th } \\
\text { percentile }\end{array}$ & Maximum \\
\hline \multicolumn{11}{|l|}{ Vitamins (unit/kg) } \\
\hline Vitamin A (IU) & 379 & 7,721 & 1.93 & 2.13 & $2,119.621$ & 480 & 6,650 & 8,000 & 9,000 & 22,400 \\
\hline Vitamin D (IU) & 380 & 2,445 & 3.06 & 13.6 & 918.711 & 150 & 1,928 & 2,500 & 3,086 & 11,900 \\
\hline Vitamin E (IU) & 376 & 45.7 & 1.04 & 1.14 & 31.474 & 0.80 & 20.2 & 45.0 & 60.0 & 240 \\
\hline Vitamin K (mg) & 345 & 4.43 & 8.86 & 8.86 & 22.112 & 0.45 & 2.00 & 2.40 & 3.64 & 400 \\
\hline Thiamine (mg) & 215 & 1.49 & 1.49 & 1.66 & 0.669 & 0.01 & 1.00 & 1.50 & 1.68 & 4.55 \\
\hline Riboflavin (mg) & 343 & 4.68 & 1.25 & 1.38 & 1.663 & 0.90 & 3.60 & 4.80 & 5.60 & 10.0 \\
\hline Vitamin $B_{6}(\mathrm{mg})$ & 295 & 2.44 & 2.44 & 2.71 & 1.528 & 0.02 & 1.28 & 2.72 & 3.20 & 16.0 \\
\hline Vitamin $B_{12}(\mu \mathrm{g})$ & 160 & 53.6 & 3.57 & 3.83 & 315.826 & 1.60 & 14.6 & 20.0 & 22.4 & 3,500 \\
\hline Pantothenic acid (mg) & 311 & 17.2 & 1.43 & 1.56 & 7.749 & 0.18 & 12.0 & 16.0 & 20.0 & 42.8 \\
\hline Niacin (mg) & 286 & 23.2 & 2.32 & 2.56 & 9.765 & 0.60 & 16.0 & 24.0 & 28.0 & 75.0 \\
\hline Folic acid (mg) & 161 & 2.37 & 1.83 & 1.98 & 2.450 & 0.14 & 0.75 & 1.60 & 4.00 & 22.1 \\
\hline Biotin (mg) & 164 & 0.43 & 2.16 & 2.27 & 0.791 & 0.03 & 0.20 & 0.32 & 0.43 & 8.00 \\
\hline Choline (mg) & 129 & 394 & 0.32 & 0.34 & 342.862 & 0.40 & 260 & 364 & 480 & 3,840 \\
\hline \multicolumn{11}{|l|}{ Trace minerals (mg/kg) } \\
\hline Copper & 366 & 18.1 & 1.81 & 3.62 & 29.129 & 1.43 & 14.0 & 15.2 & 17.5 & 393 \\
\hline Iron & 370 & 232 & 2.90 & 3.09 & 132.764 & 0.12 & 112 & 225 & 380 & 465 \\
\hline Manganese & 365 & 62.7 & 2.51 & 3.48 & 25.114 & 0.04 & 40.0 & 66.0 & 84.0 & 113 \\
\hline Zinc & 365 & 72.4 & 0.72 & 1.61 & 29.116 & 0.12 & 60.0 & 70.0 & 78.0 & 530 \\
\hline Selenium & 235 & 0.35 & 2.35 & 2.52 & 0.282 & 0.03 & 0.24 & 0.30 & 0.35 & 2.50 \\
\hline lodine & 237 & 1.32 & 9.40 & 10.1 & 1.515 & 0.03 & 0.40 & 0.64 & 1.20 & 5.35 \\
\hline
\end{tabular}

The $\mathrm{N}$ represents the number of farms; SD, standard deviation.

1) All reported values are on an as-fed basis and represent vitamins and trace minerals provided the following per kilogram of diet for pigs.

2) Values represent average supplementation rates as a proportion to dietary vitamin and trace mineral requirements recommendation from the NRC [7]

3) Values represent average supplementation rates as a proportion to dietary vitamin and trace mineral requirements recommendation from the China's

Feeding Standard of Swine [9].

Feeding Standard. The minimum supplementation values of vitamins and trace minerals were well below requirements. The average of their maximum supplementation was 46.2 and 50.8 times that of NRC and China's Feeding Standard, respectively.

The supplementation rates of vitamins and trace minerals in boar diets are presented in Table 10. Data were obtained from 101 pig farms affiliated with 40 producers. The average fat-soluble vitamin supplementation rate was 1.13 to 12.5 times that of the NRC requirement estimates, and 1.11 to 11.4 times that of China's Feeding Standard. Vitamin D was supplemented at level of 12.5 times higher than the NRC requirement estimate, and 11.4 times higher than China's Feeding Standard. There was a high level of variation (SD $=2,570.465)$ in vitamin A supplementation among producers. The average inclusion rates of vitamins $\mathrm{A}$ and $\mathrm{E}$ met the requirements. Most water-soluble vitamins were supplemented to meet requirement estimates of the NRC or China's Feeding Standard, but choline was supplemented at 0.32 times that of the two feeding standards. Trace minerals were supplemented from 1.30 to 8.78 times that of the NRC requirement estimate, and 0.91 to 8.19 times that of China's Feeding Standard. Copper, iron, manganese, zinc, and selenium were supplemented at their required levels, and iodine was sup- plemented above requirements, at 8.78 times that of NRC guidance and 8.19 times that of China's Feeding Standard, respectively. The minimum vitamin and trace mineral supplementation levels were well below required levels. The average of their maximum supplementation level was 8.66 and 8.59 times over the NRC and China's Feeding Standard requirements, respectively.

\section{DISCUSSION}

In the present study, a wide range of vitamin and mineral premixes were available to pork producers in China. However, some producers reported excessive dietary vitamin A, vitamin $\mathrm{D}$, and trace minerals supplementation, which was expected. We revealed that producers violated the legal restrictions for vitamins and trace minerals supplementation, which was not the original intention of this study. Further, this may affect the profits of companies and is not key in this discussion section. In terms of the impact of the pig industry on the environment and strict environmental regulations, Chinese nutritionists and producers are focusing on efficiently reducing the excretion of nutrients while maintaining productivity.

We found a high inclusion rate and variation of vitamin 
Table 9. The composition of supplemented vitamin and trace minerals in lactation diets

\begin{tabular}{|c|c|c|c|c|c|c|c|c|c|c|}
\hline Item $^{1)}$ & $\mathbf{N}$ & Average & $\begin{array}{l}\text { Ratio to } \\
\text { NRC }^{2)}\end{array}$ & $\begin{array}{l}\text { Ratio to } \\
\text { CHN }^{3)}\end{array}$ & SD & Minimum & $\begin{array}{l}\text { The 25th } \\
\text { percentile }\end{array}$ & Median & $\begin{array}{l}\text { The 75th } \\
\text { percentile }\end{array}$ & Maximum \\
\hline \multicolumn{11}{|l|}{ Vitamins (unit/kg) } \\
\hline Vitamin A (IU) & 374 & 5,457 & 2.73 & 2.66 & $1,693.699$ & 350 & 4,700 & 5,425 & 5,953 & 22,400 \\
\hline Vitamin D (IU) & 374 & 2,437 & 3.05 & 11.9 & 904.496 & 150 & 1,838 & 2,575 & 3,100 & 6,860 \\
\hline Vitamin E (IU) & 372 & 46.3 & 1.05 & 1.03 & 32.539 & 0.08 & 22.8 & 45.0 & 60.0 & 240 \\
\hline Vitamin K (mg) & 332 & 4.47 & 8.95 & 8.95 & 14.920 & 0.45 & 2.00 & 2.58 & 4.55 & 200 \\
\hline Vitamin $B_{6}(\mathrm{mg})$ & 287 & 2.40 & 2.40 & 2.40 & 1.647 & 0.02 & 1.20 & 2.50 & 3.20 & 18.0 \\
\hline Vitamin $B_{12}(\mu \mathrm{g})$ & 146 & 79.4 & 5.29 & 5.29 & 436.557 & 0.40 & 12.0 & 19.6 & 23.0 & 3,500 \\
\hline Pantothenic acid (mg) & 301 & 17.0 & 1.42 & 1.42 & 7.366 & 0.19 & 12.2 & 16.0 & 19.1 & 40.0 \\
\hline Niacin (mg) & 279 & 23.6 & 2.36 & 2.30 & 11.698 & 0.60 & 16.0 & 24.0 & 30.0 & 99.0 \\
\hline Folic acid (mg) & 147 & 2.45 & 1.89 & 1.82 & 2.988 & 0.14 & 0.80 & 1.40 & 3.40 & 22.1 \\
\hline Iron & 362 & 235 & 2.94 & 2.94 & 137.445 & 0.12 & 116 & 203 & 390 & 790 \\
\hline Manganese & 356 & 63.6 & 2.54 & 3.18 & 25.667 & 0.03 & 42.1 & 69.0 & 85.0 & 166 \\
\hline Zinc & 355 & 71.6 & 0.72 & 1.40 & 26.678 & 0.12 & 60.0 & 70.0 & 78.0 & 460 \\
\hline Selenium & 223 & 0.35 & 2.35 & 2.35 & 0.285 & 0.03 & 0.25 & 0.30 & 0.35 & 2.50 \\
\hline lodine & 226 & 1.44 & 10.3 & 10.3 & 1.704 & 0.03 & 0.40 & 0.71 & 1.21 & 10.2 \\
\hline
\end{tabular}

The $\mathrm{N}$ represents the number of farms; SD, standard deviation.

1) All reported values are on an as-fed basis and represent vitamins and trace minerals provided the following per kilogram of diet for pigs.

${ }^{2}$ V) Values represent average supplementation rates as a proportion to dietary vitamin and trace mineral requirements recommendation from the NRC [7].

${ }^{3)}$ Values represent average supplementation rates as a proportion to dietary vitamin and trace mineral requirements recommendation from the China's

Feeding Standard of Swine [9].

A. Vitamin A is extremely important for protection of the epithelium, ovulation, implantation, embryonic and fetal development, immunocompetence, and cell growth and differentiation [14]. The active metabolite of vitamin A, retinoic acid, has a role in a broad spectrum of biological functions, and vitamin A deficiency can severely affect health; thus, commercial sources of vitamin A supplementation are usually kept at a high level. The review by Flohr et al [15] carried out using data obtained from main producers in the United States, found high inclusion rates and variation in vitamin A values. Median vitamin A inclusion rate for piglets and growing-finishing pigs in China is similar to the U.S. [15], but it is lower (by about 0.5 times) than American industry in the breeding herd. Here, the SD of vitamin D ranged widely from 841.848 to $1,726.648$, which indicates a very wide range of variation. Our results indicate that in China there are probably two well-defined positions: While some producers use relatively high concentrations of vitamin $\mathrm{D}$, others use a much lower level. The situation in the U.S. is the same: Based on a survey by Flohr et al [15], median vitamin $\mathrm{D}$ supplementation in most stages was similar to Chinese producers, but median vitamin $\mathrm{D}$ supplementation for growing-finishing stages in China was 2 to 3 times that of the American industry. The main functions of vitamin D include the regulation of calcium and phosphorus absorption and boosting the immune response $[4,16]$. The role of vitamin $\mathrm{D}$ as an immune system regulator was suggested in early studies with the discovery of expression of vitamin $\mathrm{D}$ receptor signaling in immune cells. A previous study reported the early interferon response to rotavirus infection and the effect of vitamin D on host-pathogen interactions. They found that vitamin D supplementation could alleviate the negative effects caused by porcine rotavirus challenge [17]. They observed that supplementation with high concentrations of vitamin $\mathrm{D}$ in the diet improved the fecal consistency of the challenged pigs and decreased the secretion of proinflammatory cytokines. This led to high concentrations of vitamin D supplementation in diets. Most terrestrial animals acquire vitamin $\mathrm{D}$ by its production in skin under the influence of UV light from the sun. Pigs may not have requirements of vitamin D in dietary sources if sufficient sunlight exposure is provided in modern pig farms [18]; this may be a reason for companies to use low levels of vitamin $\mathrm{D}$ in pig diets. In the present study, median vitamin E supplementation in China's companies was lower than American producers which was reported by Flohr et al [15]. Due to the limited the "space" of formulation for premix, vitamin E supplementation has considerable variation. In addition, vitamin 
Table 10. The composition of supplemented vitamin and trace minerals in boar diets

\begin{tabular}{|c|c|c|c|c|c|c|c|c|c|c|}
\hline Item ${ }^{1)}$ & $\mathbf{N}$ & Average & $\begin{array}{l}\text { Ratio to } \\
\text { NRC }^{2)}\end{array}$ & $\begin{array}{l}\text { Ratio to } \\
\text { CHN }^{3)}\end{array}$ & SD & Minimum & $\begin{array}{l}\text { The 25th } \\
\text { percentile }\end{array}$ & Median & $\begin{array}{l}\text { The 75th } \\
\text { percentile }\end{array}$ & Maximum \\
\hline \multicolumn{11}{|l|}{ Vitamins (unit/kg) } \\
\hline Vitamin A (IU) & 99 & 7,071 & 1.77 & 1.77 & $2,570.465$ & 1,300 & 5,500 & 6,650 & 8,800 & 14,000 \\
\hline Vitamin D (IU) & 99 & 2,500 & 12.5 & 11.4 & 841.848 & 150 & 2,000 & 2,600 & 3,075 & 4,000 \\
\hline Vitamin E (IU) & 99 & 49.9 & 1.13 & 1.11 & 36.291 & 3.00 & 24.0 & 48.0 & 60.0 & 240 \\
\hline Vitamin K (mg) & 87 & 3.08 & 6.16 & 6.16 & 1.800 & 0.45 & 2.00 & 2.50 & 3.80 & 10.4 \\
\hline Thiamine (mg) & 60 & 1.45 & 1.45 & 1.45 & 0.624 & 0.40 & 1.00 & 1.42 & 1.78 & 3.00 \\
\hline Riboflavin (mg) & 90 & 4.66 & 1.24 & 1.33 & 1.697 & 1.60 & 3.85 & 4.80 & 6.00 & 8.00 \\
\hline Vitamin $B_{6}(\mathrm{mg})$ & 73 & 2.25 & 2.25 & 2.25 & 1.178 & 0.54 & 1.16 & 2.34 & 3.19 & 5.00 \\
\hline Vitamin $B_{12}(\mu \mathrm{g})$ & 41 & 17.0 & 1.13 & 1.13 & 6.128 & 5.00 & 13.6 & 20.0 & 20.0 & 28.0 \\
\hline Pantothenic acid (mg) & 73 & 19.0 & 1.59 & 1.59 & 8.459 & 7.20 & 13.0 & 16.0 & 27.2 & 45.0 \\
\hline Niacin (mg) & 77 & 21.4 & 2.14 & 2.14 & 7.579 & 3.60 & 15.6 & 20.8 & 28.0 & 35.0 \\
\hline Folic acid (mg) & 41 & 2.94 & 2.26 & 2.26 & 4.666 & 0.22 & 0.64 & 1.28 & 5.00 & 28.8 \\
\hline Biotin (mg) & 39 & 0.30 & 1.51 & 1.51 & 0.182 & 0.04 & 0.20 & 0.26 & 0.40 & 0.80 \\
\hline Choline (mg) & 30 & 401 & 0.32 & 0.32 & 130.690 & 200 & 280 & 400 & 485 & 700 \\
\hline \multicolumn{11}{|l|}{ Trace minerals (mg/kg) } \\
\hline Copper & 99 & 15.8 & 3.15 & 3.15 & 3.304 & 3.00 & 13.8 & 16.0 & 17.5 & 27.0 \\
\hline Iron & 99 & 237 & 2.96 & 2.96 & 143.529 & 0.13 & 120 & 210 & 387 & 760 \\
\hline Manganese & 98 & 61.7 & 3.09 & 3.09 & 26.134 & 0.03 & 40.0 & 62.0 & 80.0 & 160 \\
\hline Zinc & 97 & 68.5 & 1.37 & 0.91 & 22.688 & 30.0 & 57.0 & 64.0 & 70.0 & 220 \\
\hline Selenium & 65 & 0.39 & 1.30 & 2.61 & 0.660 & 0.10 & 0.26 & 0.32 & 0.37 & 1.35 \\
\hline lodine & 64 & 1.23 & 8.78 & 8.19 & 1.479 & 0.10 & 0.38 & 0.56 & 1.11 & 5.18 \\
\hline
\end{tabular}

The $\mathrm{N}$ represents the number of farms; SD, standard deviation.

1) All reported values are on an as-fed basis and represent vitamins and trace minerals provided the following per kilogram of diet for pigs.

2) Values represent average supplementation rates as a proportion to dietary vitamin and trace mineral requirements recommendation from the NRC [7].

3) Values represent average supplementation rates as a proportion to dietary vitamin and trace mineral requirements recommendation from the China's

Feeding Standard of Swine [9].

$\mathrm{E}$ is a well-known antioxidant and free-radical scavenger $[7,18]$. The high inclusion rate of vitamin $E$ adopted by some producers was intended to alleviate the stress responses of pigs and improve immune function. A higher level of vitamin $\mathrm{E}$ is particularly important for improving lipid stability in meat. However, supplementation of vitamin E should be adjusted according to the unsaturated fatty acid and antioxidant content of feed, and according to the processing and storage of pork. The NRC has established requirements of $0.5 \mathrm{mg}$ vitamin $\mathrm{K}$ per $\mathrm{kg}$ feed for all ages and productive phases [7]. Limited data have been published on optimal vitamin $\mathrm{K}$ supplementation for pigs in good physiological condition and maintained in adequate production conditions. The present survey revealed that vitamin $\mathrm{K}$ is commonly and largely added because of the common occurrence of mold toxins in cereal grains, a factor that compromises the blood-clotting mechanism and reduces intestinal synthesis in pigs. In addition, vitamin $\mathrm{K}$ is fortified above NRC recommendation, which takes account of degradation of vitamin $\mathrm{K}$ during storage and feed processing $[12,13]$. The variation of this vitamin is relatively high. The situation in the U.S. is different: Flohr et al [15] reported that manufacturers always add high levels of vitamin $\mathrm{K}$ in feed, at about 4 to 8 times that of the required levels.
Water-soluble vitamins are not stored in the body and need to be provided continuously to maximize metabolic efficiency and prevent vitamin deficiencies $[7,18]$. There were low variations in the supplementation rates of thiamine, riboflavin, vitamin $\mathrm{B}_{6}$, folic acid, and biotin throughout the life of pigs. Most producers provide these vitamins close to the requirements, and they observed optimum growth under commercial feeding conditions. Previous studies reported that high levels of dietary supplementation of B vitamins could not improve performance, and NRC levels for pigs are sufficient to meet their needs $[19,20]$. A similar situation was described in a survey carried out in the United States [15], where some producers do not include thiamine, vitamin $B_{6}$, folic acid, and choline (mainly for growing-finishing pigs). The median value in this case for piglets and breeders was 3.1 and $2.2 \mathrm{mg} / \mathrm{kg}$ thiamine of feed, respectively; 4.0 and 3.3 $\mathrm{mg} / \mathrm{kg}$ vitamin $\mathrm{B}_{6}$ of feed, respectively; 1.5 and $1.7 \mathrm{mg} / \mathrm{kg}$ folic acid of feed, respectively; and 166.8 to 187.0 and 519.2 to $584.1 \mathrm{mg} / \mathrm{kg}$ choline of feed, respectively. There is an interesting difference between the situation described in the United States and China. Further, Flohr et al [15] found riboflavin was included in all cases in the United States, and the median value was 1.18 to 1.93 times that of China's industry. It was observed that the supplementation levels of 
niacin, vitamin $\mathrm{B}_{6}$, and choline in the diets of most life stages were lower than the NRC requirements, but were closed to China's Feeding Standard requirement. This observation means China's pigs require lower levels of niacin, vitamin $\mathrm{B}_{6}$, and choline from the vitamin premix than American pigs. In fact, Chinese pork producers routinely supplement plant sources or plant by-products in feed, and the abundance of vitamins in these ingredients have been ignored (although some of them have low bioavailability), when vitamin premixes are used as the vitamin source in diets of pigs. In addition, these vitamins have gained little attention from producers, because reducing the level of these vitamins does not affect animal's performance. Considering the cost of formulation, a low concentration of vitamins is provided to China's pigs. In addition, the median supplementation rate of vitamin $B_{12}$ in the current case was slightly lower than in the United States, as reported by Flohr et al [15]. The high inclusion rates of vitamin $B_{12}$ reported by some producers were to promote reproduction [21]. This led to a large variation in vitamin $B_{12}$ supplementation rates in the breed phases. Except in the gilt-development period, choline was supplemented below the required level. As a common B vitamin in feed, choline serves as a methyl group donor and a precursor of phosphatidylcholine, which is involved in very low-density lipoprotein assembly in the liver $[7,18]$. Although the improvement in growth performance and the decrease in liver lipid content as a result of choline supplementation in poultry rations are well established, studies of choline in pigs are limited and the results are inconsistent $[18,22]$. Thus, there was a high level of variation in choline supplementation rates in each life phase. It is considered that microbial synthesis in the digestive system is sufficient to meet the needs of these animals $[1,18]$. Nevertheless, when animals are produced in confined conditions, with little possibility of contact with feces, and particularly when animals are young and digestive flora are not well established, administration independent of the animal's own production is recommended.

Unlike other nutrients, trace elements cannot be generated in the body by de novo synthesis $[11,23]$. Pigs need to regularly ingest them from their diet, or they may deplete their body store and develop deficiency. The high inclusion rates for copper and zinc reported for some producers were used to promote growth and to help control gut pathogens [24,25]. This led to a large variation in copper and zinc supplementation rates. There are environmental concerns associated with such high dietary levels of metals; indeed, some producers adjusted inclusion rates of copper and zinc in their formulation. Flohr et al [15] found that the high inclusion rates of copper and zinc from American producers were used for growth promotion, and the situation in the United States is similar to that of China. The survey by Flohr et al [15] shows that the concentration of iron provided in feed in the United States; the median value of iron in this case is identical to that in China. In this survey, we noticed a high supplementation of manganese from some producers. We speculated that they may be used to improve pork color and reduce oxidant stress. Manganese is a constituent of superoxide dismutase, essential for the synthesis of chondroitin sulfate, and a constituent of mucopolysaccharides in the bone matrix $[4,7]$. Manganese is a species mineral problem (i.e., poultry) and is therefore of only minor interest to pig health [18], but a study indicated that feeding a supplement of manganese (350 mg/kg of feed) above the maintenance requirements of pigs does not beneficially affect their performance but may improve pork color and delay discoloration of pork during retail display [26]. In a recent article that studied the actual situation of vitamins and trace minerals in American industry, the supplementation rate of manganese was found to be similar in the United States and China. The emergence in the last 10 years of the use of supplemental vitamin $\mathrm{E}$ and selenium in pig diets and their roles in the protection of cellular and subcellular membranes from peroxidative damage have been of the utmost importance $[7,18]$. This may be the most likely reason for the high inclusion rates of selenium in the pig diet. In this study, the 0.3 to $0.4 \mathrm{mg} / \mathrm{kg}$ of selenium were supplemented for most pig life stages, which is the same situation as that reported by Flohr et al [15], who found approximately $0.3 \mathrm{mg} / \mathrm{kg}$ selenium included in most cases in the United States. This dosage meets the requirement for young pigs, but the selenium requirement for finishing pigs and breeding pigs is about twice as high. In China, there is a legal allowance of $0.5 \mathrm{mg} / \mathrm{kg}$ selenium to be included in diet, and this restricts flexibility in terms of addressing the selenium requirements of finishing and breeding pig. Chinese producers routinely add 0.3 to 0.4 $\mathrm{mg} / \mathrm{kg}$ of selenium in the finishing stage for improving meat quality characteristics such as reducing drip loss and increasing antioxidant stability. Besides, it seems likely that reproducing sows and boars are sensitive to selenium, and selenium plays an important role in the maintenance of semen quality and improved antioxidant defense of sows via specific antioxidant protective mechanisms. In pig production, it is difficult for animals to lack iodine, and low variation of iodine supplementation was observed in the present study. All companies added amounts are below the baseline of legal regulation in pig industry of China. The median inclusion rate of iodine in China's companies is slightly higher than American companies. Trace minerals are normally supplemented into animal diets as inorganic salts, primarily as oxides, sulfates, and carbonates [11,23]. Although information about the source of these nutrients is not available in the present study, the bioavailability of any given mineral in these salts is generally high, but trace minerals vary with 
the form of salt. This may be the cause of the variation of trace mineral supplementation among producers.

There has been interest in reducing the supplementation of vitamins and trace minerals from the pig diets. In the current study, the withdrawal of one or more vitamins and trace minerals in diets has been reported. The reason for this is the increasing awareness of the detrimental effects of the excessive minerals to the environment, as well as the soaring cost of vitamins. It has been demonstrated that removing vitamins and trace minerals from some life stages does not affect the pig performance response [27-30]. These are some reasons the lack of performance response resulting from vitamin fortification. The feed ingredients may contain adequate bioavailable levels of one or more vitamins or their precursors [7]; the microorganisms in the digestive tract of adult pigs may synthesize adequate amounts under feeding conditions; dietary prebiotics may alter the intestinal microbiota and their synthesis of vitamins [31]; and the vitamin may be synthesized in sufficient quantities by body tissues in some cases. We believe that the amounts of these vitamins that are present in grains are sufficient for normal growth, but they should be supplemented in diets for breeding pigs. Besides, the average supplementation of vitamins and trace minerals by most producers are relatively close to the commercial vitamin and trace mineral recommendations. Pig producers may wish to include higher levels of vitamin and trace mineral than those listed by the NRC estimates and Feeding Standard of Swine to ensure adequate intake of them and for insurance purposes. In practice, a margin of safety may be added to the stated requirements to account for variability in vitamin and trace mineral content and bioavailability, the presence of inhibitors in ingredients, inadequate processing or mixing of diets, partial loss of vitamins from storage, the impact of environmental stressors on vitamin and trace mineral requirements, and other factors.

\section{CONCLUSION}

The levels of vitamins and trace minerals used or recommended in China's pig industry by private agencies vary widely within this investigation. Most producers are supplementing at levels relatively close to commercial vitamin and trace mineral recommendations. This survey suggests a baseline of standard practice for trace mineral supplementation rates in different feeding stages in China. With this information, future research still needs to examine the vitamin and trace mineral requirements for various phases of production under large group commercial feeding conditions. In addition, this study may help producers and nutritionists to determine the vitamin and trace mineral requirements which optimize productivity of pig production and maximize economic return.

\section{CONFLICT OF INTEREST}

We certify that there is no conflict of interest with any financial organization regarding the material discussed in the manuscript.

\section{ACKNOWLEDGMENTS}

The authors are grateful for the support by the China Agricultural University Research Funding (201705510410056) and Ministry of Agriculture and Rural Affairs Funding (21178259).

\section{REFERENCES}

1. Combs GF. The vitamins: fundamental aspects in nutrition and health. 5th ed. Cambridge, MA, USA: Academic Press; 2016.

2. Varaeva YR, Livantsova EN, Ukrainets IV, Kosyura S, Starodubova AV. Metabolomics in vitamin status assessment. Curr Pharm Des 2018;24:3028-33. https://doi.org/10.2174/13816 12824666180912142743

3. Weiss WP. A 100-year review: from ascorbic acid to zincmineral and vitamin nutrition of dairy cows. J Dairy Sci 2017;100:10045-60. https://doi.org/10.3168/jds.2017-12935

4. Upadhaya SD, Kim IH. Importance of micronutrients in bone health of monogastric animals and techniques to improve the bioavailability of micronutrient supplements - a review. Asian-Australas J Anim Sci 2020;33:1885-95. https://doi.org/ 10.5713/ajas.19.0945

5. Jang YD, Rotering MJ, Isensee PK, et al. Distribution of injected fat-soluble vitamins in plasma and tissues of nursery pigs. Asian-Australas J Anim Sci 2020;33:1985-90. https:// doi.org/10.5713/ajas.19.0987

6. Kim BG, Lindemann MD. An overview of mineral and vitamin requirements of swine in the national research council (1944 to 1998) publications. Prof Anim Sci 2007; 23:584-96. https://doi.org/10.15232/S1080-7446(15)31028-7

7. Committee on Nutrient Requirements of Swine, National Research Council. Nutrient requirements of swine. 11th ed. Washington, DC, USA: National Academy Press; 2012.

8. Choi SC, Chae BJ, Han IK. Impacts of dietary vitamins and trace minerals on growth and pork quality in finishing pigs. Asian-Australas J Anim Sci 2001;14:1444-9. https://doi.org/ 10.5713/ajas.2001.1444

9. Standardization Administration of the People's Republic of China. Feeding standard of swine. NY/T 65-2004. Beijing, China: Ministry of Agriculture and Rural Affairs of the People's Republic of China; 2004.

10.Jang YD, Choi HB, Durosoy S, Schlegel P, Choi BR, Kim YY. Comparison of bioavailability of organic selenium sources in finishing pigs. Asian-Australas J Anim Sci 2010;23:931-6. 
https://doi.org/10.5713/ajas.2010.90619

11. Baker DH. Bioavailability of minerals and vitamins. In: Lewis AJ, Southern LL, editors. Swine nutrition. Washington, DC, USA: CRC Press; 2000. pp. 377-400.

12. Yang P, Wang HK, Zhu M, Li LX, Ma YX. Degradation kinetics of vitamins in premixes for pig: effects of choline, high concentrations of copper and zinc, and storage time. Anim Biosci 2021;34:701-13. https://doi.org/10.5713/ajas.20.0026

13. Yang P, Wang H, Zhu M, Ma Y. Evaluation of extrusion temperatures, pelleting parameters, and vitamin forms on vitamin stability in feed. Animals 2020;10:894. https://doi.org/10. 3390/ani10050894

14. Erkelens MN, Mebius RE. Retinoic acid and immune homeostasis: a balancing act. Trends Immunol 2017;38:168-80. https://doi.org/10.1016/j.it.2016.12.006

15. Flohr JR, DeRouchey JM, Woodworth JC, Tokach MD, Goodband RD, Dritz SS. A survey of current feeding regimens for vitamins and trace minerals in the US swine industry. J Swine Health Prod 2016;24:290-303.

16. Christakos S, Dhawan P, Verstuyf A, Verlinden L, Carmeliet G. Vitamin D: metabolism, molecular mechanism of action, and pleiotropic effects. Physiol Rev 2016;96:365-408. https:// doi.org/10.1152/physrev.00014.2015

17.Zhao Y, Yu B, Mao X, et al. Effect of 25-hydroxyvitamin $\mathrm{D}_{3}$ on rotavirus replication and gene expressions of RIG-I signalling molecule in porcine rotavirus-infected IPEC-J2 cells. Arch Anim Nutr 2015;69:227-35. https://doi.org/10.1080/ 1745039X.2015.1034522

18. McDowell LR. Vitamins in animal nutrition: comparative aspects to human nutrition. 2nd ed. San Diego, CA, USA: Academic Press; 2000.

19. Jeong JH, Hong JS, Han TH, Fang LH, Chung WL, Kim YY. Effects of dietary vitamin levels on physiological responses, blood profiles, and reproductive performance in gestating sows. J Anim Sci Technol 2019;61:294-303. https:/doi.org/ 10.5187/jast.2019.61.5.294

20.Böhmer BM, Roth-Maier DA. Effects of high-level dietary B-vitamins on performance, body composition and tissue vitamin contents of growing/finishing pigs. J Anim Physiol Anim Nutr 2007;91:6-10. https://doi.org/10.1111/j.14390396.2006.00635.x

21.Simard F, Guay F, Girard CL, Giguère A, Laforest JP, Matte JJ. Effects of concentrations of cyanocobalamin in the gestation diet on some criteria of vitamin $B_{12}$ metabolism in first- parity sows. J Anim Sci 2007;85:3294-302. https://doi.org/ 10.2527/jas.2006-523

22.Li W, Li B, Lv J, Li D, Zhang L, Wang T. Choline supplementation improves the lipid metabolism of intrauterine-growthrestricted pigs. Asian-Australas J Anim Sci 2018;31:686-95. https://doi.org/10.5713/ajas.15.0810

23. Baker DH, Stein HH. Bioavailability of minerals and vitamins in feedstuffs. In: Chiba LI, editor. Sustainable swine nutrition. 1st ed. Ames, Iowa: Wiley-Blackwell; 2013. pp. 341-64.

24. Hill GM, Mahan DC, Carter SD, et al. Effect of pharmacological concentrations of zinc oxide with or without the inclusion of an antibacterial agent on nursery pig performance. J Anim Sci 2001;79:934-41. https://doi.org/10.2527/2001.794934x

25. Shelton NW, Tokach MD, Nelssen JL, et al. Effects of copper sulfate, tri-basic copper chloride, and zinc oxide on weanling pig performance. J Anim Sci 2011;89:2440-51. https://doi. org/10.2527/jas.2010-3432

26. Sawyer JT, Tittor AW, Apple JK, et al. Effects of supplemental manganese on performance of growing-finishing pigs and pork quality during retail display. J Anim Sci 2007;85:104653. https://doi.org/10.2527/jas.2006-262

27. Mahan DC, Carter SD, Cline TR, et al. Evaluating the effects of supplemental B vitamins in practical swine diets during the starter and grower-finisher periods-a regional study. J Anim Sci 2007;85:2190-7. https://doi.org/10.2527/jas.20070118

28. Ma YL, Lindemann MD, Webb SF, Rentfrow G. Evaluation of trace mineral source and preharvest deletion of trace minerals from finishing diets on tissue mineral status in pigs. Asian-Australas J Anim Sci 2018;31:252-62. https:// doi.org/10.5713/ajas.17.0189

29. Gowanlock DW, Mahan DC, Jolliff JS, Moeller SJ, Hill GM. Evaluating the $\mathrm{NRC}$ levels of $\mathrm{Cu}, \mathrm{Fe}, \mathrm{Mn}$, and $\mathrm{Zn}$ using organic minerals for grower-finisher swine. J Anim Sci 2013;91:56806. https://doi.org/10.2527/jas.2013-6608

30. Yang P, Zhao J, Wang H, Li L, Ma Y. Effects of vitamin forms and levels on vitamin bioavailability and growth performance in piglets. Appl Sci 2020;10:4903. https://doi.org/10.3390/ app10144903

31.LeBlanc JG, Milani C, de Giori GS, Sesma F, van Sinderen D, Ventura M. Bacteria as vitamin suppliers to their host: a gut microbiota perspective. Curr Opin Biotechnol 2013;24:1608. https://doi.org/10.1016/j.copbio.2012.08.005 